\title{
Electronic commerce-enabled supply chain process integration and business value
}

\begin{abstract}
Purpose: The purpose of this paper is to develop and test a model to analyze the relationships between three aspects of technical electronic commerce (EC)-based information system (IS) resources; the supply chain process integration; and business value.

Design/methodology/approach: The paper is consistent with the perspective on IS-enabled organizational capabilities and resource based view of the firm. A questionnaire-based survey was conducted to collect data from 214 supply chain, logistics, or procurement/purchasing managers of leading manufacturing firms.
\end{abstract}

Findings: The findings suggest that supply chain process integration, a key EC-enabled organizational capability, can enhance business value. We found that this capability serve as a catalyst in transforming technical EC-based IS resources (technical quality of EC applications, EC advancements, and EC alignment) into higher value for a firm.

Research limitations/implications: Among other limitations, this paper does not address human IS resources as the other potential determinants of firm's supply chain capabilities. Moreover, this study relies on cross-sectional data.

Practical implications: The results suggest that supply chain process integration is an important intermediate organizational capability through which value of EC-based IS resources can be materialized. The technical aspects of EC-based IS resources need to be developed to effectively form supply chain capabilities.

Originality/value: The paper is perhaps one of the first to show theoretically and empirically how firms, in particular in developing countries, can generate business value from ECenabled supply chain process integration; also it broadens the scope of EC alignment in relation to process integration and business value to the entire supply chain.

Keyword: Manufacturing industries; Managers; Electronic commerce; Information systems; Supply chain integration; Business value; Business performance; Resource-based view 